\title{
Alonso, José., Joven, Fernando., Fajardo, Luis. y Panero, María. (Coords.), Martín Lutero. Perspectivas desde el s. XXI, Valladolid: Ediciones Universidad de Valladolid, 2018, 478 pp.
}

\author{
José Antonio Abreu Colombri \\ Universidad de Alcalá, España \\ abreucolombri@gmail.com
}

La obra, Martín Lutero. Perspectivas desde el s. XXI, reúne muchas de las ponencias del Congreso Internacional: Martín Lutero. 500 años de la Reforma Protestante (celebrado en Valladolid, entre el 16 y 18 de octubre de 2017). Los cuatro coordinadores (José Luis Alonso Ponga, Fernando Joven Álvarez, Luis Fajardo Vaquero y María Pilar Panero García) estructuran la publicación en dos bloques temáticos: "teología" y "cultura". Trece son los capítulos que componen el primer bloque y ocho capítulos conforman el segundo, con una extensión de casi quinientas páginas.

Las bibliografías, situadas al final de cada trabajo individual, erigen una secuencia de estratos historiográficos de los últimos ciento veinte años. Dichos elementos documentales, esencialmente, representan la faceta más miscelánea del trabajo colectivo sobre la figura del reformador alemán y los efectos del movimiento protestante.

En la forma y en el fondo, la obra va en la misma línea que la mayoría de estudios y productos editoriales surgidos en el marco de celebración del quinto centenario del estallido de la gran Reforma protestante en Europa. La investigación, gestada entre la comunidad académica vallisoletana, tiene el enfoque típico de las investigaciones históricas y teológicas del catolicismo, pero con resultados de investigación alejados del oficialismo vaticano en la mayoría de los casos. La tradición historiográfica española y la reiteración de objetos de investigación está muy presente en la conformación de la obra. Los investigadores participantes tienen diferentes áreas de trabajo, vínculos institucionales y filiaciones confesionales, aunque, en ningún caso, se detallan datos biográficos a lo largo de la publicación.

Los organismos colaboradores son presentados de manera abierta: Ayuntamiento de Valladolid, Fundación Miguel Delibes, Cátedra de Estudios sobre la Tradición, Estudio Teológico Agustiniano de Valladolid, Centro Internacional de Estudios de Religiosidad Popular y Organización del $500^{\circ}$ de la Reforma Protestante.

En la introducción general, los coordinadores de la publicación, básicamente, tratan de dejar claro que la disposición de los elementos principales guarda relación con las mesas y los ejes temáticos del congreso. Por lo tanto, las reflexiones expuestas en las actas congresuales están encauzadas por los cuatro objetivos principales recogidos en la convocatoria: estudiar los diferentes elementos teológicos del pensamiento luterano y el contexto en el que se desenvolvió el proceso reformador, considerar los grandes aportes realizados por Lutero y sus seguidores a la cultura y la lengua, analizar la importancia del luteranismo en España y reflexionar sobre las principales interpretaciones del origen del protestantismo surgidas en la actualidad.

El área de temas teológicos, al margen de algunas cuestiones relacionadas con la historia del pensamiento cristiano y la organización eclesiástica, se aborda de lleno el mundo del reformador alemán y la trascendencia

Recepción: 24 de agosto de 2019 | Aprobación: 10 de octubre de 2019 | Publicación: 15 de enero de 2020 
de su obra doctrinal y exegética. Los trabajos individuales se centra en el concepto de la fe y el sentido de la moral, la construcción socio-cultural del protestantismo, las negociaciones entre Roma y Lutero y el establecimiento de las bases del posterior debate ecuménico, la interpretación bíblica de Lutero y la divulgación de sus interpretaciones, la percepción católica del ecumenismo protestante en la actualidad, la teología cristiana y la interdisciplinariedad de las ciencias sociales y las humanidades, la tradición intertextual iniciada por la primera generación de reformadores, la presencia de algunos fundamentos de la teológica medieval en la obra luterana, los factores psicológicos que condicionaron las vivencias y las percepciones de Lutero y la historiografía actual sobre la Reforma.

También, los usos, las reutilizaciones y las apropiaciones de conceptos teológicos entre católicos y protestantes tienen un amplio desarrollo, así como el liderazgo y la influencia de los primeros reformadores sobre las posteriores fases históricas del protestantismo. Llama poderosamente la atención, después de tantas décadas de constantes historiográficas, como los marcos de investigación siguen siendo muy excluyentes y focalizados sobre la región europea occidental. Prácticamente, las diferentes variantes teológicas del protestantismo, en el tiempo histórico y en el espacio geográfico, no tienen cabida en los capítulos de esta investigación.

Los aspectos culturales ocupan el segundo bloque temático, a modo de "cajón de sastre", y aglutinan cuestiones vinculadas entre sí y sin ningún tipo de nexo: el legado de la Reforma en el pensamiento de la Edad Moderna y la Edad Contemporánea, el impacto cultural del protestantismo en la sociedad europea del Renacimiento, los efectos de la obra de Lutero sobre los humanistas italianos, los teólogos españoles frente al planteamiento de ruptura con Roma, los valores cristianos en el constitucionalismo estadounidense, la violencia política y la intolerancia religiosa ante la pujanza cultural del protestantismo y, reiterativamente, la perspectiva católica sobre el orden social y la gestión eclesiástica de las comunidades protestantes.

Nuevamente, pero esta vez en el espacio de temas culturales, los trabajos aportados tienen un lectura en clave europea, sin tomar en consideración manifestaciones coetáneas y sin establecer un marco comparativo con los estudios culturales sobre el protestantismo como fenómeno global y sobre el concepto de evangelización universal. Tampoco aparecen muchas referencias del impacto de la Reforma sobre las sucesivas transiciones y remociones de los sistemas de creencias surgidos en las diferentes ramificaciones protestantes. El sujeto y el objeto de las investigaciones se imbrican en muchos casos y modelos de análisis, pero tienen un recorrido temático bastante limitado, por la reiteración de estereotipos conceptuales y el estudio de fases históricas muy concretas en España y en Europa.

La obra carece de una conclusión final y, por tanto, no se produce un aporte reflexivo, por parte de los cuatro coordinadores que han dado forma a esta interesante y extensa publicación. Hay grandes temas de investigación que no tienen ningún tipo de repercusión en la presente obra, a pesar de que han alcanzado un gran desarrollo en el plano académico de los países anglosajones de las últimas décadas. Por poner un ejemplo, el impacto cultural del protestantismo en la región de Norteamérica se despacha con un único capitulo, que profundiza en la presencia de valores protestantes en la configuración del sistema político estadounidense.

Los veneros intelectuales del estudio de las Reformas protestantes provienen, de forma más o menos clara, de los viejos modelos de investigación histórica surgidos en España, Italia y Alemania, durante la segunda mitad del siglo XIX y comienzos del siglo XX. Los epígrafes más logrados de la contribución colectiva son los que hacen referencia a la industria del libro, a la traducción intertextual y a la germinación multicultural del protestantismo. Se puede afirmar que la obra establece como uno de sus mayores objetivos el rastreo de los itinerarios ideológicos y teológicos determinados por Martín Lutero a lo largo de toda su vida. 